\title{
Hypersensitivity of azo dyes in urticaria patients based on a single-blind, placebo-controlled oral challenge
}

\author{
Beata Sadowska, Marika Gawinowska, Marlena Sztormowska, Marta Chełmińska
}

Department of Allergology, Medical University of Gdansk, Gdansk, Poland

Adv Dermatol Allergol 2022; XXXIX (5): 877-879

DOI: https://doi.org/10.5114/ada.2021.11026

\begin{abstract}
Introduction: The role of azo dyes in urticaria is not fully understood.

Aim: To assess the incidence rate of hypersensitivity reactions to food azo dyes based on a placebo-controlled oral challenge in a group of patients with suspected urticaria exacerbation after consuming food additives.

Material and methods: The study included patients over 18 years of age with chronic urticaria, in whom hypersensitivity to food additives was suspected based on a questionnaire and medical history. Patients suspected of urticaria exacerbations after ingestion of azo dyes were enrolled in a placebo-controlled single-blind oral challenge (OC) with a mixture of azo food dyes: tartrazine, Quinoline Yellow, Sunset Yellow, Cochineal Red, Allura Red, and azorubine. Results: Out of 110 patients ( 76 women and 34 men, mean age 46.1 (20-76 years), 39 patients were qualified for the oral challenge. We observed two subjects (5.1\%) with a positive result.

Conclusions: Azo dyes ingested in food or medications incidentally cause urticaria but may exacerbate its course. Oral challenge-confirmed hypersensitivity to azo dyes is much less common than reported by patients.
\end{abstract}

Key words: food additives, urticaria, tartrazine, Quinoline Yellow, Sunset Yellow, Cochineal Red.

\section{Introduction}

Chronic urticaria (CU) is a heterogeneous disease, the causes of which are not fully understood. There are many observations regarding the influence of food additives, including azo dyes, on the course of CU. Hypersensitivity reactions to food additives occur most often after consuming processed, ready-made, or restaurant products, and only occasionally after meals prepared at home from known ingredients [1].

Azo dyes are commonly used additives in the food, pharmaceutical, and clothing industries to give products a durable and attractive color to consumers. They are mainly used to produce beverages, sweets, processed foods and medicines (Table 1). Over the past 50 years, the amount of synthetic dyes used in food has increased by $500 \%$ [2]. Originally, azo dyes were derived from coal $\operatorname{tar}$ [3], but now they are synthetically produced with the presence of formaldehyde, aniline, hydroxide, and sulfuric acid [2].

In 2007, McCann et al. in a study conducted at the University of Southampton in the UK, observed an adverse effect on concentration and attention in children of the following azo dyes: tartrazine (E 102), Quinoline Yellow (E 104), Sunset Yellow (E 110), azorubine (E 122), Cochineal Red A (Ponceau 4R, E 124) and Allura Red AC (E 129), since then called 'Southampton dyes' [4].

Azo food dyes are also being investigated for induction of hypersensitivity reactions. The immune mechanism has not been identified so far, and due to their low molecular weight, they may act rather like haptens [1, 3]. It is suspected that several mechanisms are involved, and perhaps some responses are dose-dependent [1]. They can also be absorbed through the skin from cosmetic and pharmaceutical products [2]. Nettis et al. demonstrated in a double-blind placebo-controlled trial that the rate of hypersensitivity to tartrazine was about 1\% [5].

Apart from urticaria and angioedema, rhinitis and conjunctivitis, bronchospasm, exacerbation of atopic eczema, persistent erythema, leukocytoclastic vasculitis, granulomatous changes and anaphylaxis have been observed $[1,2,6]$. To date, few studies on hypersensitivity to azo dyes in urticaria have been published. However, patients with urticaria often point to colored products, such as sweets or drinks, as the causes of higher urticaria activity.

Address for correspondence: Beata Sadowska MD, Department of Allergology, Medical University of Gdansk, 17 Mariana Smoluchowskiego St, 80-214 Gdansk, Poland, e-mail: sadowska.beata@yahoo.pl Received: 11.07.2021, accepted: 25.07.2021. 
Table 1. The use of azo dyes in food

\begin{tabular}{|c|c|c|c|c|c|c|}
\hline Food & E 102 & 104 & E 110 & E 122 & E 124 & E 129 \\
\hline Cheese & + & + & & + & & \\
\hline $\begin{array}{l}\text { Fishery and crustacean } \\
\text { products }\end{array}$ & + & + & + & + & + & + \\
\hline $\begin{array}{l}\text { Canned fruit or } \\
\text { vegetables }\end{array}$ & + & & & + & & + \\
\hline Alcohol drinks & + & + & + & + & + & + \\
\hline Non-alcoholic drinks & & + & + & + & + & + \\
\hline Food supplements & & + & + & & + & \\
\hline Dietary foods & & + & + & & & \\
\hline Confectionary & & + & + & & + & \\
\hline Mostarda di frutta & & + & + & & + & \\
\hline $\begin{array}{l}\text { Meat and fish vegetable } \\
\text { analogues }\end{array}$ & & + & + & & + & \\
\hline Milk products & & + & + & & + & \\
\hline Chewing gum & & + & + & & + & \\
\hline Seasonings & & + & & & & \\
\hline Coatings for meat & & & + & & + & \\
\hline Sausages & & & & & + & + \\
\hline $\begin{array}{l}\text { Health marking of fresh } \\
\text { meat }\end{array}$ & & & & & & + \\
\hline
\end{tabular}

E 102 - tartrazine, E 104 - Quinoline Yellow, E 110 - Sunset Yellow, E 122 - azo rubine, E 124 - Cochineal Red A (Ponceau 4R), E 129 - Allura Red AC.

\section{Aim}

The present study aimed to determine whether consumption of a mixture of 'Southampton azo dyes' influences urticaria based on a single-blind, placebocontrolled oral challenge.

\section{Material and methods}

One hundred and ten patients with chronic urticaria suspected of being hypersensitive to food additives were qualified for the study. All the patients fulfilled the detailed questionnaire regarding the course of the urticaria and possible culprit factors. The subjects were hospitalized in the Department of Allergology of the Medical
University of Gdansk in 2017-2019. Each participant gave written informed consent to participate in the study. The study protocol was approved by the Bioethics Committee (NKBBN/546/2016-2017) and was in line with the principles of ethics and the Helsinki Declaration.

Patients did not take antihistamines for 7 days and systemic glucocorticoids 1 month before hospitalization. Subjects with active urticaria within the last 3 days were not enrolled in the study.

Patients suspected of exacerbation of urticaria after ingestion of azo dyes were qualified for oral, single-blind, placebo-controlled challenge (OC). This group included patients who reported processed colored food, certain medications, sweets and infection as aggravating factors. Each subject was given an intravenous line. The oral challenge was performed according to the following protocol: at $9.00 \mathrm{am}$, placebo capsules were administered; then, in the absence of side effects, after a minimum of $2 \mathrm{~h}$, a mixture of six azo dyes - tartrazine, Quinoline Yellow, Sunset Yellow FCF, Cochineal Red A, Allura Red AC, and azorubine (Ipra France SA, Poland Branch) - was given. Ten percent of the acceptable daily intake (ADI) of each dye placed in a single non-transparent capsule was used as verum, and the dose was calculated for a patient with a bodyweight of $70 \mathrm{~kg}$ (Table 2). The test was considered positive if an allergist confirmed urticaria and/or angioedema symptoms within the next $24 \mathrm{~h}$ and in the absence of a reaction after placebo.

\section{Results}

There were 39 oral challenges carried out in the study group. Two non-atopic patients were positive.

\section{Patient 1}

A 53-year-old male patient reported hives and angioedema every $2-4$ weeks since 1 year ago. The symptoms usually develop within a few hours of consuming alcohol or during infection, when he was taking colored cough syrups. Six hours after verum ingestion, the patient experienced upper lip edema and generalized urticaria within the next $2 \mathrm{~h}$. During prior hospitalization, he was diagnosed with aspirin hypersensitivity based on

Table 2. Content of azo dyes in 1 capsule used in oral challenge

\begin{tabular}{|c|c|c|c|}
\hline Variable & ADI $[\mathrm{mg} / \mathrm{kg} / \mathrm{day}]$ & $\begin{array}{c}\text { ADI calculated for a patient } \\
\text { weighing } 70 \mathrm{~kg}\end{array}$ & $\begin{array}{l}10 \% \text { of ADI calculated for a patient } \\
\text { weighing } 70 \mathrm{~kg} \text { placed in capsule }\end{array}$ \\
\hline E 102 - tartrazine & 7.5 & 525 & 52.5 \\
\hline E 104 - Quinoline Yellow & 0.5 & 35 & 3.5 \\
\hline E 110 - Sunset Yellow & 1 & 70 & 7 \\
\hline E 122 - azorubine & 4 & 280 & 28 \\
\hline E 124 - Cochineal Red A & 0.7 & 49 & 4.9 \\
\hline E 129 - Allura Red AC & 7 & 490 & 49 \\
\hline
\end{tabular}

$A D I$-acceptable daily intake. 
angioedema following $1000 \mathrm{mg}$ of aspirin administration during an oral challenge. Currently, the patient remains on a low-salicylate diet, avoids non-steroidal anti-inflammatory drugs, and since avoiding azo food dyes, he has achieved almost complete relief of his ailments.

\section{Patient 2}

In a 64-year-old female patient, symptoms of urticaria and angioedema had occurred several times a year for 10 years. The patient could not link the symptoms to any triggering factor except for consuming artificially colored sweets up to $2 \mathrm{~h}$ before skin lesion eruptions. Oral aspirin challenge that was previously carried out was negative. Ninety minutes after the administration of verum, she developed urticaria within the arm and thigh and reported severe itching in the back.

\section{Discussion}

In the present study, we demonstrated that azo dyes could exacerbate the course of urticaria in $5.1 \%$ of challenged patients, representing $1.8 \%$ of all patients with suspected food additive hypersensitivity in the studied cohort.

We used a mixture of dyes, because in everyday life patients often consume several food additives simultaneously, e.g., eating colorful sweets. One study showed that more than $10 \%$ of commercially processed products contained five or more additives, demonstrating broad consumer exposure to mixtures of various food additives [7]. We considered using a dye mixture safe due to the expected low rate of reactions and their milder manifestation compared to a typical food allergy [8]. Carrying out a challenge with each dye separately would be difficult for patients to accept due to the hospitalization length. Antihistamines' discontinuation a few days before the challenge may provoke a false positive provocation test [1]. This situation did not apply to our patients with a positive challenge test result because both patients 1 and 2 used antihistamines symptomatically.

Among the 'Southampton dyes' tested, the most reactions have been reported after administration of tartrazine [1]. The verum tartrazine content in our study was $1 / 10$ of the ADI dose and was high enough ( $52.5 \mathrm{mg}$ ) to induce a hypersensitivity reaction. Simon suggested in the challenge protocol $50 \mathrm{mg}$ as the maximum dose of azo dye [9].

In the analysis of the azo dyes' mechanism of action, increasing histamine release from basophils has been suggested. Matsuo et al. reported that tartrazine, like aspirin, increased histamine release from basophils through increased Syk kinase activation, regardless of its effect on cyclooxygenase-1 activity [10], but only after incubation with specific anti-lgE antibodies. They found that aspirin, some non-steroidal anti-inflammatory drugs, Sunset Yellow, and tartrazine without anti-IgE activation increased the secretion of histamine from basophils by less than $5 \%$ only. Further, activation of basophils in this study with specific anti-lgE antibodies increased the release of histamine by about 30-40\%, and the addition of aspirin, tartrazine, or sodium benzoate resulted in a further, dose-dependent histamine increase from basophils. This experience could partially explain why patients with active urticaria may react to selected food additives, while the reactions may not be reproducible in the future. In other words, after the acute disease has subsided, the same patient may tolerate the same food additives that previously exacerbated urticaria. Indeed, the mechanism of action of azo pigments in urticaria requires further research.

\section{Conclusions}

The present study showed that azo dyes ingested in food incidentally may exacerbate its course. Oral challenge-confirmed hypersensitivity to azo dyes is much less common than reported by patients.

\section{Conflict of interest}

The authors declare no conflict of interest.

\section{References}

1. Feketea G, Tsabouri S. Common food colorants and allergic reactions in children: myth or reality? Food Chem 2017; 230: 578-88.

2. Vojdani A, Vojdani C. Immune reactivity to food coloring. Altern Ther Health Med 2015; 21 Suppl 1: 52-62.

3. Bosso JV, Robertson DM. Urticaria, angioedema, and anaphylaxis provoked by food additives. In: Food Allergy: Adverse Reactions to Foods and Food Additives. Fifth edition. Metcalfe DD, Sampson HA, Simon RA, Lack G (eds). WileyBlackwell 2014; 346-60.

4. McCann D, Barrett A, Cooper A, et al. Food additives and hyperactive behaviour in 3-year-old and 8/9-year-old children in the community: a randomised, double-blinded, placebocontrolled trial. Lancet 2007; 370: 1560-7.

5. Nettis E, Colanardi MC, Ferrannini A, Tursi A. Suspected tartrazine-induced acute urticaria/angioedema is only rarely reproducible by oral rechallenge. Clin Exp Allergy 2003; 33: 1725-9.

6. Gultekin F, Doguc DK. Allergic and immunologic reactions to food additives. Clin Rev Allergy Immunol 2013; 45: 6-29.

7. Chazelas E, Deschasaux M, Srour B, et al. Food additives: distribution and co-occurrence in 126,000 food products of the French market. Sci Rep 2020; 10: 3980.

8. Cardinale F, Mangini F, Berardi M, et al. Intolerance to food additives: an update. Minerva Pediatr 2008; 60: 1401-9.

9. Simon RA. Additive-induced urticaria: experience with monosodium glutamate (MSG). J Nutr 2000; 130 (4S Suppl): 1063S-6S.

10. Matsuo H, Yokooji T, Morita H, et al. Aspirin augments lgEmediated histamine release from human peripheral basophils via Syk kinase activation. Allergol Int 2013; 62: 503-11. 